\title{
Diagnóstico das concepções e das práticas de biossegurança entre alunos do IFRS - Campus Porto Alegre
}

Cassiano Pamplona Lisboa Instituto Federal de Educação, Ciência e Tecnologia do Rio Grande do Sul (IFRS) Campus Porto Alegre (cassiano.lisboa@poa.ifrs.edu.br)

Karin Tallini Instituto Federal de Educação, Ciência e Tecnologia do Rio Grande do Sul (IFRS) Campus Porto Alegre (karin.tallini@poa.ifrs.edu.br)

Carmynie Barros e Xavier Instituto Federal de Educação, Ciência e Tecnologia do Rio Grande do Sul (IFRS) Campus Porto Alegre (carmynie@gmail.com)

Resumo: O diagnóstico das concepções e das práticas de biossegurança entre estudantes usuários dos laboratórios de ensino do IFRS - Campus Porto alegre é de suma importância para a elaboração de um programa de sensibilização em biossegurança a ser aplicado na Instituição. Os alunos ingressantes nos cursos Técnicos em Biotecnologia e Segurança do Trabalho, e no curso superior de Licenciatura em Ciências da Natureza formam a amostra estudada por pertencerem a um grupo de risco, uma vez que, os profissionais egressos dessas áreas poderão trabalhar em ambientes laboratoriais, tendo maior exposição a agentes químicos, físicos e biológicos em relação à população em geral. A exploração do campo de pesquisa foi realizada através do acompanhamento das aulas práticas e da realização de entrevistas por meio de questionários. Além disso, para a coleta dos dados, utilizou-se anotações em diário de campo e gravações (de áudio) das entrevistas. Analisandose os resultados dos questionários, pode-se perceber que mais de $30 \%$ dos alunos ingressantes apontaram ter conhecimento sobre biossegurança e também sobre a separação de resíduos laboratoriais. Em contrapartida, apenas $12,7 \%$ dos entrevistados indicaram conhecer o termo biossegurança. Todos os participantes da pesquisa consideraram importante a presença da disciplina biossegurança no currículo dos respectivos cursos, contudo, a maioria não identificou o laboratório como um local perigoso.

Palavras-chave: Laboratório; Condições de Trabalho; Pesquisa Qualitativa. 


\title{
Diagnosis of biosafety concepts and practices of IFRS students, Campus Porto
}

\begin{abstract}
Alegre
Abstract: The diagnosis of conceptions and practices of biosafety among students and users of IFRS - Campus Porto Alegre teaching laboratories is of utmost importance for the elaboration of a biosafety awareness program to be applied in the Institution. Students entering the Technical courses in Biotechnology, Occupational Safety; and a degree in Natural Sciences, forming a sample studied because they belong to a risk group, since the graduated professionals are areas of work in laboratory environments, having greater exposure of chemical, physical and biological agents in relation to the general population. The exploration of the field of research was accomplished through the monitoring of practical practices and the accomplishment of interviews through questionnaires. In addition, data collection and recording (audio) interviews were used for data collection. By analyzing the results of the questionnaires, it can be seen that more than $30 \%$ of the incoming students pointed out to have knowledge about biosafety and also about the separation of laboratory residues. On the other hand, only $12.7 \%$ of respondents indicated that they knew the term biosafety. All participant of the study considered important the presence of the biosafety discipline without curriculum of transposition of courses, however, most did not identify the laboratory as a dangerous place.
\end{abstract}

Keywords: Laboratory; Working Conditions; Qualitative Research.

\section{INTRODUÇÃO}

Segundo Andrade e Sanna (2007), a preocupação inicial dos profissionais da área da saúde encontra-se relacionada ao surgimento da Biossegurança como campo do saber que abordava as doenças transmissíveis, tendo o enfoque maior para o risco biológico, permanecendo esse destaque atualmente. Em um estudo realizado por Soares (2008), o conceito de Biossegurança está relacionado à minimização dos riscos de contaminação, através de um conjunto de medidas, envolvendo o meio ambiente e acidentes pessoais nos locais de trabalho. De acordo com a Organização Mundial da Saúde - OMS (2004), para uma adequada proteção biológica é necessário que as práticas de segurança sejam eficazes, pois servem de base para o sistema envolvido com a matéria Biossegurança:

Através de avaliações de risco efetuadas como parte integrante do programa de segurança biológica de uma instituição, recolhe-se informação sobre o tipo de organismos disponíveis, [...] identificação das pessoas [...] responsáveis. [...] Para cada serviço, é preciso preparar e implementar um programa específico sobre proteção biológica em laboratório, segundo as exigências do serviço, o tipo de trabalho realizado, e as condições locais. (OMS, 2004, p. 60). 
Dessa forma, o contato com a biossegurança deve acontecer desde o início da formação, pois o aprendizado científico acontece por aproximações sucessivas e pela reconstrução permanente do conhecimento ao longo da escolaridade. A educação em biossegurança e suas atualizações são hoje fundamentais para a conscientização e mudança de hábito entre os usuários de laboratórios, pois exige uma modificação cultural para a adoção de medidas preventivas, devendo-se identificar e gerir os riscos. (GIR et al., 2004; FARIAS e ZEITOUNE, 2005; SILVA et al., 2015).

Alguns autores abordam essa temática de gerenciamento de riscos laboratoriais enfatizando a necessidade de capacitação dos recursos humanos, a exemplo disso, afirmou Mastroeni (2006):

A falta de uma cultura prevencionista tem sido o principal obstáculo para as pessoas agirem com precaução nos locais de trabalho. Muitos trabalhadores são admitidos sem treinamento e passam a exercer funções sem estarem familiarizados com os procedimentos dos serviços, contribuindo para o aumento do risco nas atividades. [...] Em virtude do fator humano ser a principal causa de acidentes em laboratórios, o maior esforço deve ser concentrado na educação, visto que alguns trabalhadores tendem a menosprezar os riscos, levando em consideração somente a execução do experimento. [...] A melhor proteção que podemos oferecer ao trabalhador é a informação e treinamento, pois nada valerá uma parafernália de equipamentos de proteção se estes forem incorretamente empregados. (MASTROENI, 2006, p. 04).

De acordo com Araújo (2007), muitos desafios são impostos à educação decorrente das modificações que são observadas no mundo do trabalho. Nesse sentido, cabe às instituições de ensino reconsiderar suas atribuições de modo a colocarem à disposição dos alunos meios que os tornem cognitivamente hábeis $\mathrm{e}$ capazes de adotar condutas diante das muitas situações. Para que um aluno tenha a capacidade de utilizar conhecimentos científicos na resolução de problemas de ordem prática, é preciso que a escola se responsabilize em repassar as informações necessárias para subsidiar e incentivar seus atos de maneira responsável, criativa e crítica. Ainda nesse sentido, a instituição escolar se torna um espaço onde o aluno desenvolve a criatividade, sensibilidade e a imaginação, fatores primordiais para a construção de um trabalhador mais capacitado para o exercício da cidadania (ARAÚJO, 2007). O educandário assume, portanto, um papel de destaque na construção de uma sociedade democrática e, para tal, a educação surge como um 
dos pilares dessa construção, tendo em vista que é inquestionável a participação da mesma para a formação cidadã (SILVA, 2000).

Outro aspecto considerado na construção deste trabalho foi o fato do Instituto Federal de Educação Ciência e Tecnologia do Rio Grande do Sul, Campus Porto Alegre, ser uma instituição federal de ensino e, como tal, precisar se adequar as Normas Regulamentadoras (NRs) do Ministério do Trabalho em conformidade com o Manual para os Serviços de Saúde dos Servidores Civis Federais, neste caso NR 7, Programa de Controle Médico de Saúde Ocupacional, NR - 9, Programa de Prevenção de Riscos Ambientais, e, quando aplicada a área de saúde conforme os cursos da Instituição tal como o Curso Técnico em Biotecnologia, NR - 32 que trata da Segurança e Saúde no Trabalho em Serviços de Saúde. Os órgãos públicos federais, nesse sentido, assumem a responsabilidade pela gestão da qualidade das condições de trabalho do servidor público federal e a educação em biossegurança se torna fundamental para que se faça essa ligação entre o ensinar e a prática em sala de aula e em laboratórios escolares, desde espaços mais simples como laboratórios de ciência até os mais especializados como os do ensino profissionalizante e da graduação e pós-graduação.

A instituição de ensino, entendida como local que congrega muitas pessoas, é concebida para educar para a vida, o que implica na prevenção e na criação da cultura de saúde e segurança. Ações de treinamento periódico são importantes para impedir que docentes e discentes fiquem inativos e paralisados, sabendo como se portar ante a um perigo iminente e desconhecido (REIS, 2005). Os alunos formados em ambientes seguros e apoiados para desenvolverem seus potenciais, adquirem conhecimentos e competências requeridas para prevenir os riscos e as situações que podem ameaçar a sua integridade. Assim sendo, o ensino da Biossegurança pode ser uma ferramenta útil para atender a essa demanda, em especial a partir da inclusão de conteúdos adequados nos currículos escolares (HERNAN GARCIA et al., 2001).

Por fim, convém ressaltar que os laboratórios, sejam eles de ensino, pesquisa ou produção, representam um ambiente de risco, já que no mesmo espaço há equipamentos, reagentes, soluções, microorganismos, pessoas, papéis, livros, amostras, etc. Além disso, a atividades laboratoriais envolvem o manuseio de produtos químicos, vidrarias, equipamentos eletrônicos, bem como o uso de gases e a montagem de sistemas (TALLINI e LISKA, 2014). 
Tendo em mente o acima exposto, o presente artigo apresenta e discute os resultados de uma pesquisa que teve como objetivo diagnosticar as concepções e as práticas de biossegurança de estudantes usuários dos laboratórios de ensino do IFRS, Campus Porto alegre, com vistas à elaboração de um programa de sensibilização em biossegurança a ser aplicado na Instituição. O delineamento metodológico da investigação, os resultados e algumas ponderações a partir destes são apresentados nas seções que seguem.

\section{METODOLOGIA}

A investigação que subsidia as considerações apresentadas neste artigo pode ser caracterizada como de tipo qualitativo e de caráter exploratório. No contexto da metodologia qualitativa aplicada ao campo da biossegurança, é importante salientar que se emprega a concepção trazida das Ciências Humanas, segundo às quais não se busca estudar o fenômeno em si, mas entender seu significado individual ou coletivo no cotidiano das pessoas (TURATO, 2005). Nesse ínterim, torna-se indispensável saber o que os fenômenos, tais como trabalho, risco e segurança representam para elas. O significado tem função estruturante: em torno do que a situação representa, as pessoas organizarão de certo modo suas vidas, incluindo a adoção (ou não) de boas práticas no que se refere à biossegurança.

A primeira etapa da pesquisa se caracterizou pela construção e reestruturação dos instrumentos de pesquisa (questionários) até sua versão final. $O$ questionário intitulado "Levantamento Preliminar em Biossegurança" foi composto por questões abertas e fechadas sobre biossegurança e informações relacionadas ao perfil do ingressante. Sua aplicação foi acompanhada pela negociação da participação na investigação por meio de termo de consentimento livre e esclarecido. A versão final do instrumento de pesquisa pode ser visualizada na Figura 1.

$\mathrm{Na}$ etapa posterior, o questionário foi aplicado aos participantes da pesquisa: 70 estudantes ingressantes no IFRS, matriculados nos cursos de graduação em Licenciatura em Ciências da Natureza - habilitação Biologia e Química; Técnico em Segurança do Trabalho; e Técnico em Biotecnologia. Os dados foram coletados no segundo semestre de 2012, durante o intervalo das aulas dos alunos. Para a tabulação e análise dos dados foram utilizadas planilhas eletrônicas, Excel (Plus 
2010) e Microsoft Office Profissional (Plus 2010), sendo organizados em uma tabela de frequências para as variáveis dicotômicas e as porcentagens calculadas.

Figura 1 - Questionário aplicado aos alunos ingressantes (Técnico em Biotecnologia, Técnico em Segurança do Trabalho e Licenciatura em Ciências da Natureza) no IFRS Campus Porto Alegre. Fonte: elaboração própria.

Curso no IFRS:

Sexo: ( ) Masculino ( ) Feminino

Formação (marque apenas o último grau cursado)

Ensino Médio:

( ) Instituição Privada

( ) Instituição Pública

( ) Outro:

Questões:

1- Tem conhecimento sobre o significado de biossegurança? Sim ( ) Não ( )

2- Já assistiu alguma palestra e/ou aula que enfocasse sobre biossegurança? Sim ( ) Não (

3- Você já ouviu falar em separação de resíduos de laboratório? Sim ( ) Não ( )

4- Você já observou se os profissionais de laboratório utilizam algum equipamento para proteção própria ou do ambiente de trabalho? Sim ( ) Não ( ). Se Sim, cite quais:

5- Se você fosse trabalhar em um laboratório no seu curso, você saberia como se cuidar? Sim ( ) Não ( )

6- Qual a sua principal dúvida em relação à prevenção em um laboratório?

7- Você acha que todo laboratório é um local perigoso? Sim ( ) Não ( ). Justifique:

8- Você acha importante o tema biossegurança no curso que você está ingressando? Sim ( ) Não ( ). Justifique: 


\section{RESULTADOS}

Do total de entrevistados - 70 alunos ingressantes - 25 estavam matriculados no curso de graduação em Licenciatura em Ciências da Natureza: Biologia e Química ( $n=25), 25$ pertenciam ao quadro discente do curso Técnico em Segurança do Trabalho ( $n=25)$ e 20 era oriundos do curso Técnico em Biotecnologia $(n=20)$.

No que tange aos resultados da investigação, um dos primeiros aspetos a serem considerados diz respeito ao conhecimento dos discentes acerca do tema biossegurança. Conforme expressaram nos questionários, $56 \%$ dos ingressantes considerou não ter conhecimento sobre o significado de biossegurança, por não ter um contato formal com o tema ( $83 \%)$, destacando-se os alunos matriculados no curso de Licenciatura em Ciências da Natureza. Em direção semelhante, os estudantes $(60 \%)$ não identificaram o laboratório como um local perigoso.

As respostas fornecidas às demais questões apresentadas, entretanto, permitem-nos relativizar em parte os dados apresentados acima e identificar a existência de noções básicas em relação a como se portar nesse tipo de ambiente. Como exemplos e indicativos dessas noções, cerca de $83 \%$ dos estudantes sabiam que profissionais da área utilizam EPIs e $66 \%$ tinham conhecimento acerca da separação de resíduos laboratoriais (ainda que 61\% afirmaram que não saberiam se cuidar em um laboratório). Os alunos do Curso Técnico de Segurança do Trabalho apresentaram ter mais familiaridade com o termo biossegurança. Diferentemente de outros cursos, a maior parte (64\%) dos discentes reconheceu o laboratório como um ambiente perigoso, Foi unanimidade entre os entrevistados a importância do tema biossegurança no curso em que estão ingressando. Esses dados podem ser observados a seguir nas Figuras 2.1 e 2.2. As duas ilustrações possibilitam uma visão geral das informações coletadas e tabuladas ao longo do presente estudo. 
Figura 2.1 - Concepções de biossegurança entre alunos ingressantes (2012) dos cursos de Licenciatura em Ciências da Natureza, Técnico em Segurança do Trabalho e Técnico em Biotecnologia do IFRS, Campus Porto Alegre.

Percentual de alunos que consideraram ter (ou nào) conhecimento sobreo significado de Biossegurança

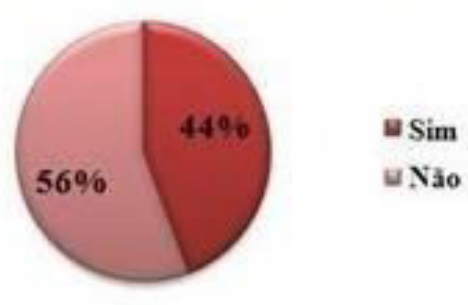

Percentual de alunosque assitiram (ou não) uma palestra ou aula de Biossegurança

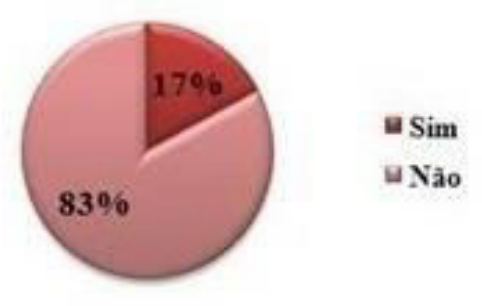

Percentual de alunos que consideraram importante 0 tema Biossegurança no curso que está ingressando

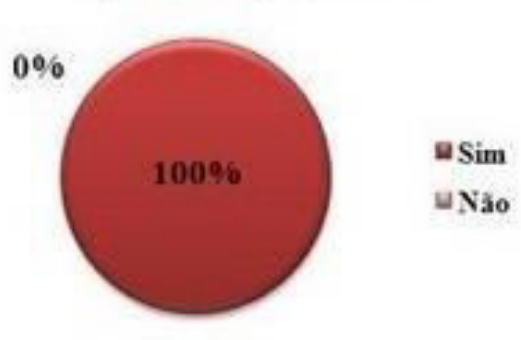

\begin{abstract}
Alunos que consideram ter (ou nào) conhecimento sobre o significado de Biossegurança em cada curso
\end{abstract}

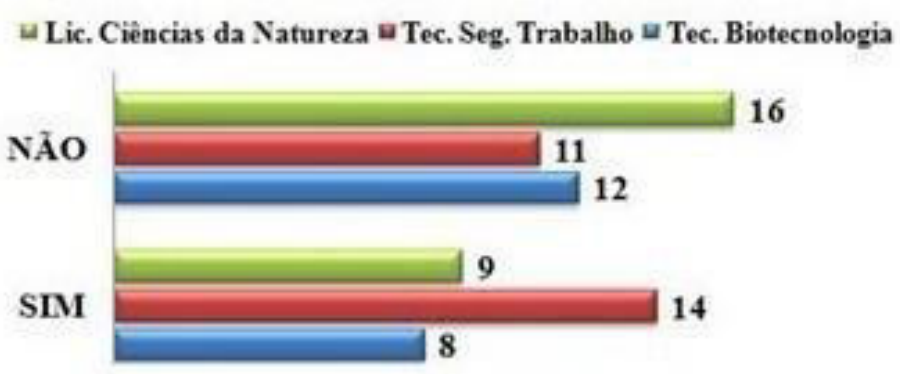

u Lic. Cièncias da Natureza $=$ Tec. Seg. Trabalho $\|$ Tec. Biotecnologia

NÃO

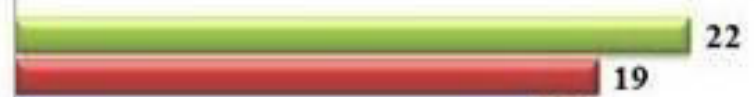

22

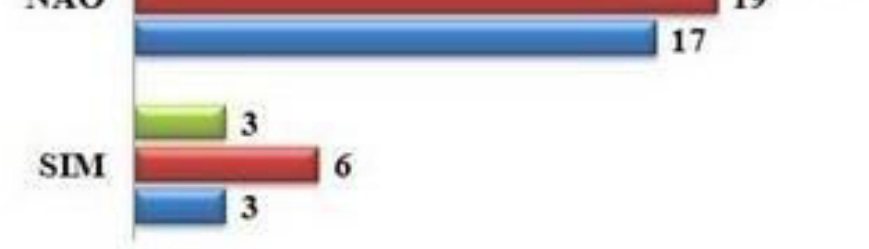

Alunos que consideraram importante (ou nào) o tema Biossegurança no curso que está ingressando

u Lic. Ciências da Natureza $=$ Tec. Seg. Trabalho $=$ Tec. Biotecnologia

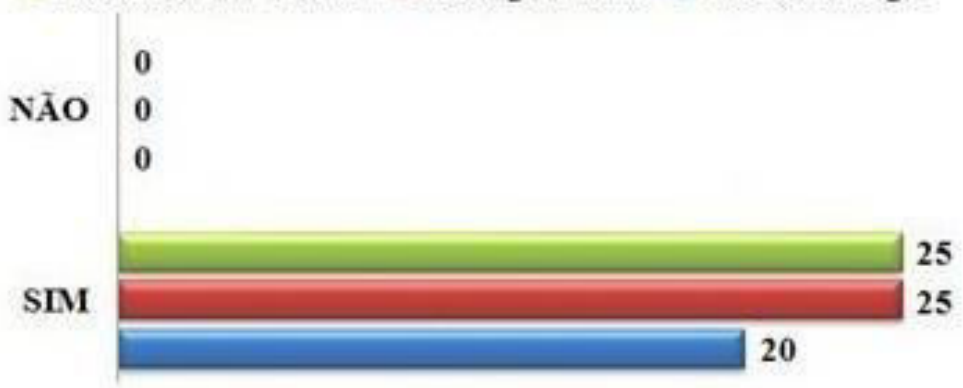

Fonte: elaboração própria. 
Figura 2.2 - Continuação das Concepções de biossegurança entre alunos ingressantes (2012) dos cursos de Licenciatura em Ciências da Natureza, Técnico em Segurança do Trabalho e Técnico em Biotecnologia do IFRS, Campus Porto Alegre.
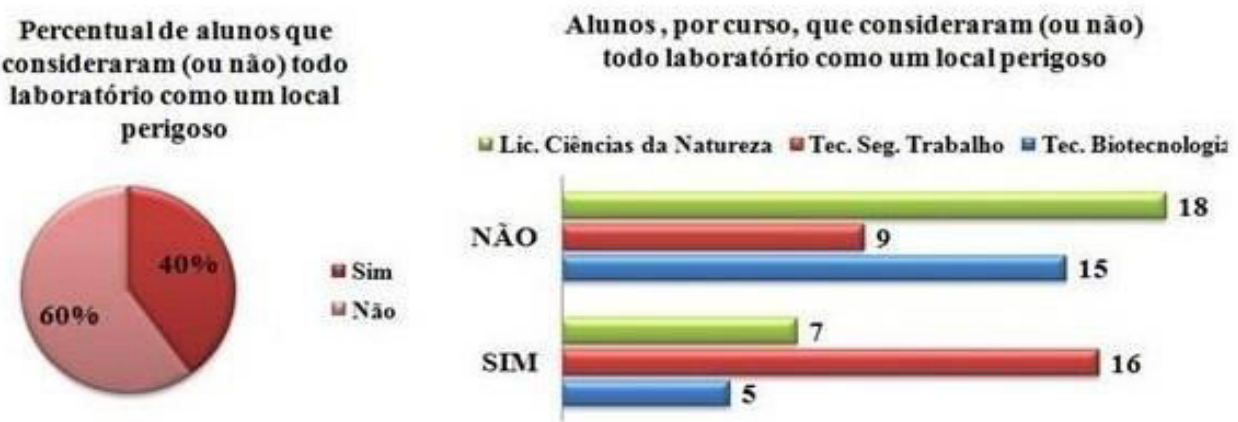

Percentual de alunos que acreditam que saberiam se cuidar (ou não) se fossem trabalhar em um laboratório
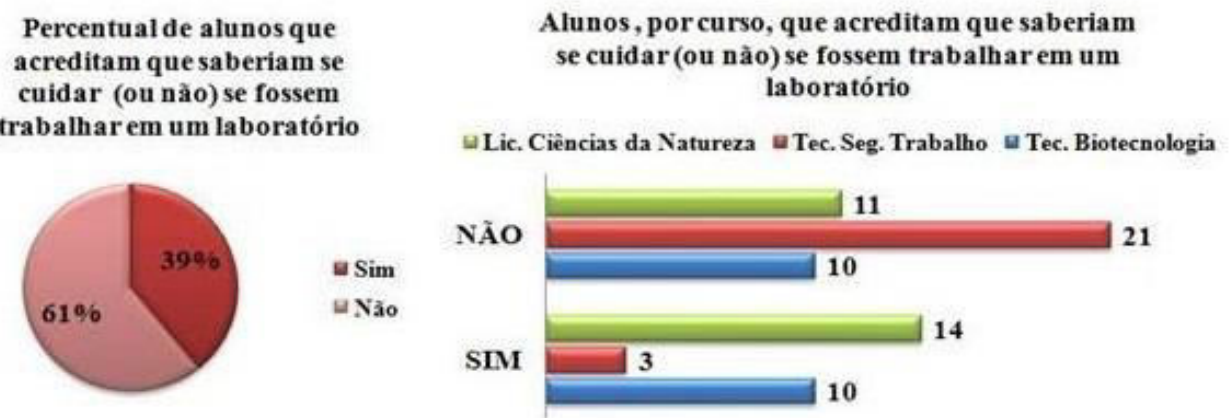

\section{Percentual de alunos que sabiam (ou não) que profissionais de laboratório} utilizam EPI

Alunos, por curso, que sabiam (ou não) que profissionais de laboratório utilizam EPI
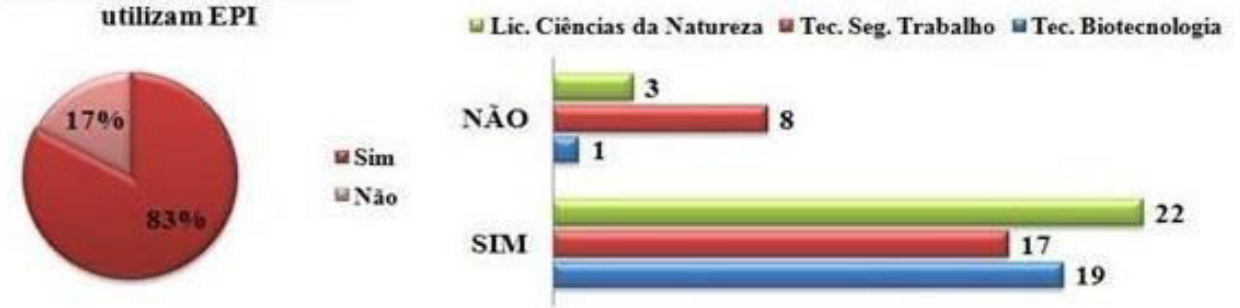

Percentual de alunos que ouviram falar (ou não) de separação de residuos laboratoriais
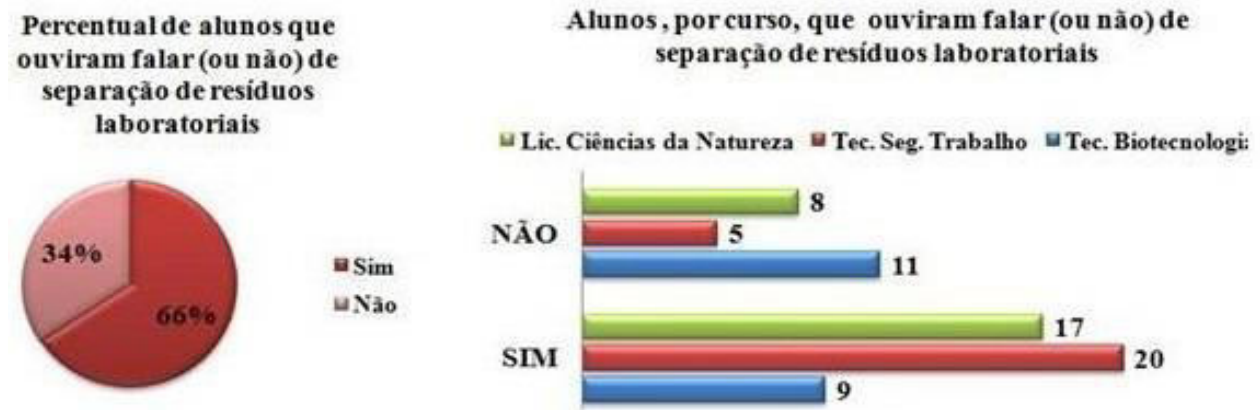

Fonte: elaboração própria. 


\section{DISCUSSÃo}

Ribeiro e colaboradores (2015) realizaram um estudo com docentes do ensino técnico em enfermagem e verificaram a predominância de três concepções de biossegurança, em ordem decrescente: como sinônimo de equipamentos de proteção individual; como proteção dos envolvidos no trabalho; e como segurança da vida. Verificaram também que o docente reproduz aprendizados escolares e toma decisões influenciadas pelos cenários de sua prática. Nesse estudo, conclui-se que os docentes entendem a importância de adotar práticas laborais seguras, e que o ensino influencia nas ações dos futuros profissionais, no entanto, a concepção de defesa da vida foi minoritária.

No estudo de Neto (2017), que investigou o conhecimento e a adesão de 343 estudantes da área da saúde às Medidas de Precaução Padrão (MPP) e a percepção dos riscos de estudantes a partir do $4^{\circ}$ período dos cursos de enfermagem, medicina e odontologia, evidenciou-se que quanto ao ensino das medidas de biossegurança no decorrer da graduação, 94\% dos entrevistados na enfermagem, $26 \%$ na medicina e $99,1 \%$ na odontologia relataram ter recebido instrução sobre medidas de biossegurança em algum momento da graduação.

No nosso estudo, todos os alunos afirmaram que no local de ensino se adotam boas práticas de biossegurança, dentre essas, a utilização dos Equipamentos de Proteção Individuais (EPl's) e Equipamentos de Proteção Coletivos (EPC's), assinalando-os conforme o requerido no instrumento de pesquisa. O trabalho de Neto (2017) mostrou que 100\% dos estudantes da enfermagem e da odontologia declararam utilizar frequentemente os EPIs, $82 \%$ dos alunos de medicina afirmaram aderir ao uso.

Ao cruzar as respostas fornecidas a diferentes perguntas, percebemos que a maioria dos ingressantes reconhecem os EPIs como um item utilizado por profissionais do laboratório, contudo não consideraram esse ambiente perigoso $(n=35)$. Pelas respostas encontradas (Figura 3), percebemos que o uso do EPI está mais associado à função desempenhada pelo trabalhador do que com a proteção que este confere. Por exemplo, o uso do jaleco está mais associado à imagem de analista clínico do que à proteção contra reagentes químicos e chamas. 
Figura 3 - Uso de EPIs e impressões sobre segurança

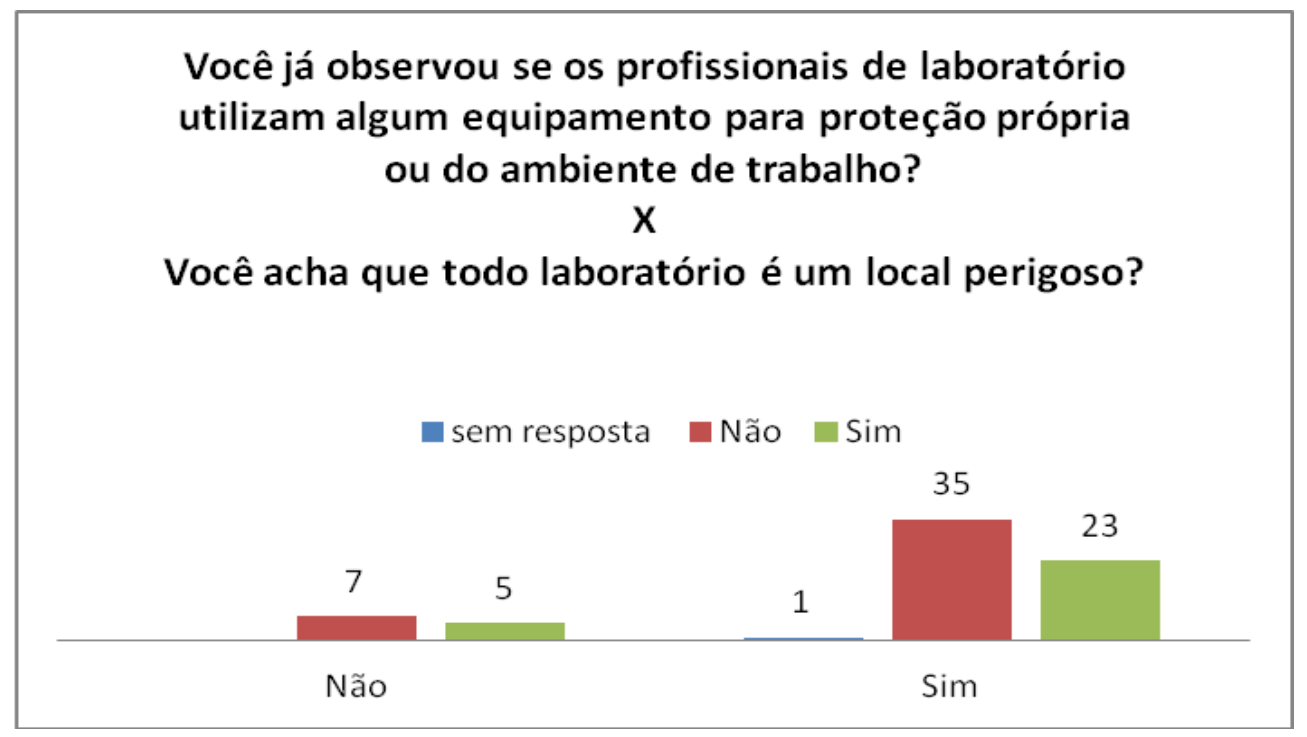

Fonte: elaboração própria.

No que se refere à utilização dos equipamentos de proteção individual, constatou-se no estudo de OLIVEIRA (2009) que os alunos do curso de enfermagem utilizaram com frequência superior a 90\%, somente a máscara e a luva, e/ou usaram de forma inadequada o gorro, os óculos e o avental. Para os alunos do curso de medicina houve resposta satisfatória quanto ao uso de luvas $(100,0 \%)$, avental $(95,0 \%)$ e máscara $(90,0 \%)$; porém o gorro e os óculos não apresentaram respostas com a mesma frequência.

A Figura 4, por sua vez, demonstra a percepção dos alunos que reconhecem o significado de biossegurança da mesma forma que consideram os EPI's como ferramentas utilizadas pelos profissionais da área. Ou seja, os indivíduos que atuam em laboratórios, minimizam os riscos e incidentes nestes ambientes, potencializando o entendimento dos frequentadores destes locais quanto ao comportamento e vestimenta requeridos.

Em linhas gerais, outros autores já afirmaram que no Brasil, a biossegurança não é adequadamente inserida nas diretrizes curriculares das instituições de ensino superior, relativas à área da saúde, principalmente nos cursos de medicina e enfermagem (PEREIRA, et al., 2010; REIS, 2013). 
Figura 4 - significados atribuídos ao termo 'biossegurança' e uso de epis.

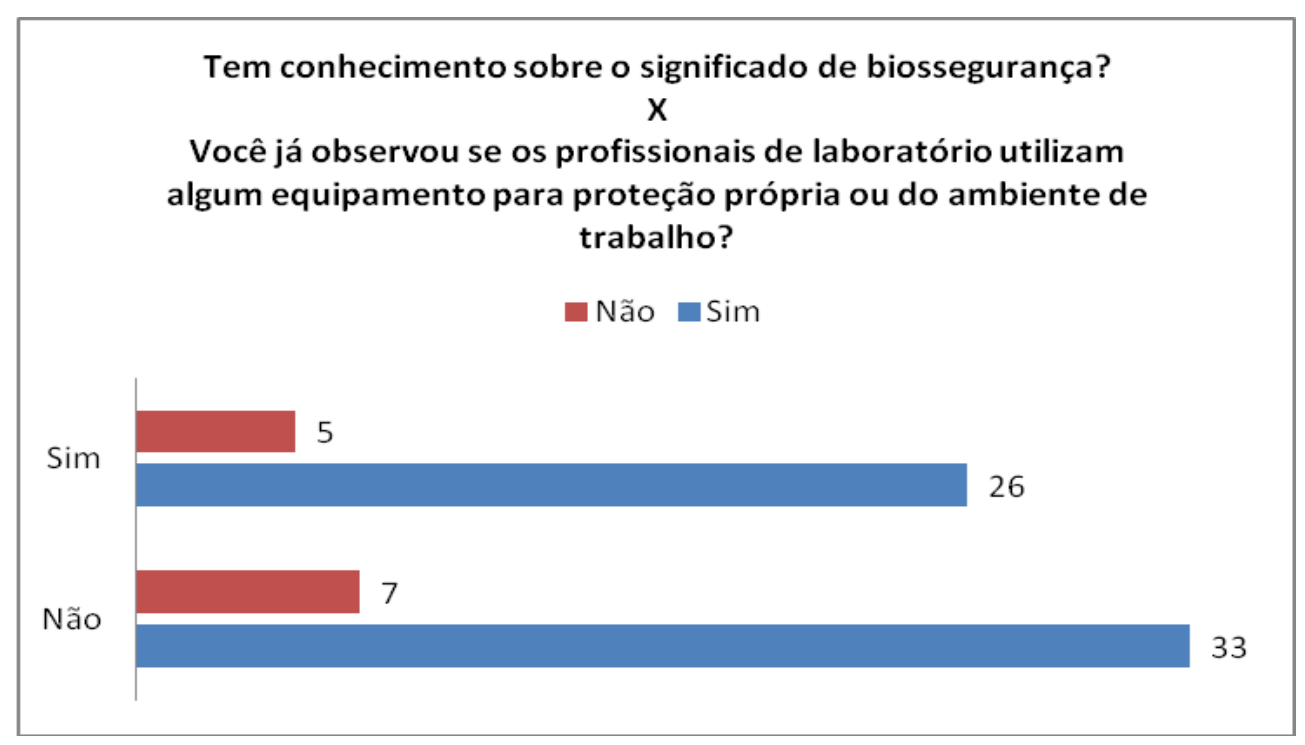

Fonte: elaboração própria.

Na pesquisa de VARGAS e colaboradores (2014) realizada na Universidade Federal de Uberlândia Campus de Patos de Minas com os acadêmicos em Biotecnologia do primeiro ao quinto período do semestre letivo de 2013 foi verificado que a maioria dos alunos ingressantes no Curso de Biotecnologia $(79,4 \%)$ considerou o tema importante, achou a disciplina necessária ao biotecnólogo e afirmou que a biossegurança promove a melhoria em laboratórios. Já quando o quando a pesquisa foi realizada após cursarem os mesmos terem cursado a disciplina de Biossegurança, os resultados demonstraram que, após os conhecimentos adquiridos, $98,04 \%$ dos discentes julgaram o tema importante e afirmaram que a disciplina é necessária ao biotecnólogo e que a biossegurança promove a melhoria em laboratórios.

Os estudantes se apresentam, em um primeiro momento, com um pensamento simplista em relação à biossegurança, uma vez que a associaram primariamente à prevenção dos acidentes vinculados ao laboratório. Nessa linha de raciocínio, reconheceram que existem consequências graves, aqui entendidas como acidentes, se não houvesse ações de biossegurança. De fato, a diminuição dos casos de acidentes em laboratórios de pesquisa tem sido o principal desafio à falta de conhecimento, que estabelece a prevenção como principal meio de controle. Muitos acadêmicos, bolsistas e estagiários estão em contato com os laboratórios sem treinamento e por isso exercem funções sem estarem familiarizados com os 
procedimentos das atividades, favorecendo o aumento do risco. MÜLLER (2004) e MARQUES (2010) relatam que é necessário que todos os envolvidos em atividades de risco tenham o conhecimento sobre as regulamentações de biossegurança e que sejam aptos a colocá-las em prática de forma efetiva.

\section{CONSIDERAÇÕES FINAIS}

A capacitação dos alunos é citada como fundamental durante o processo de formação, fazendo-se necessária a elaboração de um programa de sensibilização em biossegurança. Os entrevistados expressaram a importância de saber não apenas quais são os equipamentos de proteção, e sim, como utilizá-los de forma correta. Por unanimidade, veem na disciplina de biossegurança uma forma de incentivo, através da educação para que as práticas de risco e o comodismo sejam modificados pelas ações resultantes na proteção do discente e no seu futuro profissional.

O trabalho de Lima (2017) relata que visão de biossegurança para os estudantes de licenciatura são orientações pouco exploradas em suas formações, carecendo ampliá-las ainda na formação ou através de manuais que discutam e orientem professores e alunos da Educação Superior e/ou Básica aos cuidados que minimizem riscos de acidentes e proponham alternativas nas atividades práticas experimentais de ensino.

Desta maneira se torna necessário incorporar nos currículos dos cursos à adoção as diretrizes de biossegurança, boas práticas de laboratório e gestão de laboratório para que ao longo do tempo tenhamos profissionais com uma formação mais consciente das suas ações e as consequências no mundo do trabalho.

\section{REFERÊNCIAS}

ANDRADE, A. C.; SANNA, M. C. Ensino de biossegurança na graduação em Enfermagem: uma revisão da literatura. REBEN, 60 (5), set.-out., 2007, p.569572.

ARAÚJO, O. J. M. A prática docente e a formação cidadã. 2007. Disponível em: <https://www.webartigos.com/artigos/a-pratica-docente-e-a-formacao-cidada/1059>. Acesso em: 26 mar. 2018. 
FARIAS S. N. P.; ZEITOUNE, R. C. G. Riscos no trabalho de enfermagem em um Centro Municipal de Saúde. Revista de Enfermagem UERJ, v.13, p. 167-174, 2005.

GIR, E.; TAKAHASHI, R. F.; OLIVEIRA, M. A. C.; NICHIATA, L. Y.; CIOSAKI, S. I. Biossegurança em DST/AIDS: condicionantes da adesão do trabalhador de enfermagem às precauções. Rev. Esc. Enferm. USP. São Paulo, v.38, n.3, p. 24553, abr/mai, 2004.

HERNAN GARCIA, M.; RAMOS MONSERRAT, M.; FERNANDEZ AJURIA, A. Revisión de los trabajos publicados sobre promoción de la salud en jóvenes españoles. Rev. Esp. Salud Publica, Madrid, v. 75, n. 6, p. 491-504, nov. 2001. Disponível em <http://scielo.isciii.es/scielo.php?script=sci_arttext\&pid=S113557272001000600002\&lng=es\&nrm=iso>. Acesso em: 26 mar. 2018.

MARQUES, M. A.; COSTA, M. A.; SULDOFSKI, M. T.; COSTA, G. F. M. Biossegurança em laboratório clínico: uma validação do conhecimento dos profissionais a respeito das normas de precauções universais. RBAC2010; 42:283-6.

MASTROENI, M. F. Biossegurança aplicada a laboratórios e serviços de saúde. Atheneu. $2^{a}$ Edição. São Paulo, 2006.

MÜLLER I.C., MASTROENI M.F. Tendência de acidentes em laboratórios de pesquisa. Revista Biotecnologia Ciência e Desenvolvimento. 2004; 33:101-8.

OLIVEIRA, A. C. \& GONÇALVES, J. A. Incidência de Acidentes com Material Perfurocortante entre Alunos de Graduação em Ciencias da Saude. Cuid Saude. $2009 \mathrm{Jul} / \mathrm{Set} ;$ 8(3):385-392.

ORGANIZAÇÃO MUNDIAL DA SAÚDE. Manual de segurança biológica em laboratório. $3^{a}$ ed. Genebra: Organização Mundial da Saúde, 2004. 204 p.

PEREIRA, M. E. C.; COSTA, M. A. F.; BORBA, C. M. et al. Construção do Conhecimento em Biossegurança: uma revisão da produção acadêmica nacional na área de saúde. (1989-2009). Rev Saúde Soc. 2010; 19 (2):395- 404.

REIS, M. M. A. S. Acidentes escolares nos agrupamentos de escolas de Braga entre 1998 e 2003. 2005. 140 f. Dissertação (Mestrado) - Curso de Estudos da Criança - Promoção da Saúde e Meio Ambiente, Universidade do Minho, Braga, 2005. Disponível em

<http://repositorium.sdum.uminho.pt/bitstream/1822/3247/1/ACIDENTES OCORRIDOS NOS AGRUPAMENTOS DE ESCOLAS DE BRAGA NOS ANOS LECTIVOS 1998 a 2003.pdf>. Acesso em: 26 mar. 2018.

REIS P. G. T. A, DRIESSEN A. L, da COSTA A. C. B. A, et al. Perfil epidemiológico de acidentes com material biológico entre estudantes de medicina em um pronto-socorro cirúrgico. Rev Col Bras Cir. 2013 Jul; 40 (4):28792. 
RIBEIRO, G.; PIRES, D. E. P. \& FLÔR, R. C. Concepção de biossegurança de docentes do ensino técnico de enfermagem em um estado do sul do Brasil. Trabalho, Educação e Saúde. V 13 (3) p. 721-737. Rio de Janeiro, Set/Dez, 2015.

SILVA, Aida Maria Monteiro. Escola Pública e a formação da cidadania: possibilidades e limites. 2000. $222 \mathrm{f}$. Tese (Doutorado) - Curso de Faculdade de Educação, Pós-graduação da Faculdade de Educação, Universidade de São PauloSP.

SILVA, M. D. S.; SILVA, P. H.; OLIVEIRA, Y. R.; ABREU, M. C.; OLIVEIRA, P. V.; PACHECO, A. C. L. Biossegurança em laboratórios: uma revisão de literatura. Revista Intertox-EcoAdvisor de Toxicologia Risco Ambiental e Sociedade, v. 8, n. 2, p. 145-173, jun. 2015.

SOARES, B. E.C. Prevenção de Riscos Biológicos para os profissionais de Saúde e Perspectiva de Biossegurança. Revista Infecto Atual; Ano IX. Edição 50. Abril/Maio, 2008.

TALLINI, K.; LISKA, M. Biossegurança. In: Alessandra Nejar Bruno. (Org.).

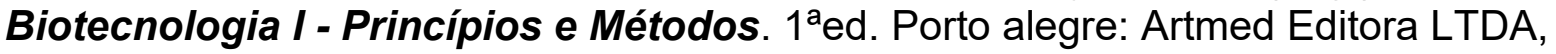
2014, v. I, p. 47-59.

TURATO, E. R. Métodos qualitativos e quantitativos na área da saúde: definições, diferenças e seus objetos de pesquisa. Revista de Saúde Pública, Campinas, v. 39, n. 3, p.507-514, abr. 2005. Disponível em:

<http://www.scielo.br/pdf/rsp/v39n3/24808.pdf>. Acesso em: 26 mar. 2018.

VARGAS, L.; RIBEIRO, M. A.; ARAÚJO, T. G. A biossegurança na opinião dos estudantes da Universidade Federal de Uberlândia; Um desafio biotecnológico. Evidência, Joaçaba v. 14 n. 2, p. 99-112, jul./dez. 2014. Disponível em: $<$ http://editora.unoesc.edu.br/index.php/evidencia/article/view/5070/pdf_16> Acesso em: 26 mar. 2018. 